\title{
CONSUMER OPINIONS ABOUT INGREDIENTS OF ORGANIC PRODUCTS
}

\author{
DOI: 10.17261/Pressacademia.2021.1411 \\ JMML- V.8-ISS.2-2021(4)-p.121-139
}

\section{Ayse Ersoy Yildirim}

Malatya Turgut Ozal University, International Business Management Department, Malatya, Turkey. ayse.yildirim@ozal.edu.tr, aysersoy@gmail.com, ORCID: 0000-0002-6895-309X

\begin{tabular}{l}
\hline Date Received: April 26, 2020 Date Accepted: February 18, 2021 \\
\hline To cite this document \\
Yildirim, A.E., (2021). Consumer opinions about ingredients of organic products. Journal of Management, Marketing and Logistics (JMML), 8(2), \\
121-139. \\
Permanent link to this document: $\underline{\text { http://doi.org/10.17261/Pressacademia.2021.1411 }}$ \\
Copyright: Published by PressAcademia and limited licensed re-use rights only.
\end{tabular}

\begin{abstract}
Purpose- The aim of this study is to examine the consumer approach towards the use of organic ingredients in the production of organic products according to sociodemographic variables.

Methodology- The sample group of the study, in which quantitative research method was used, consists of 608 female consumers in Malatya. To reach the data of the research, a questionnaire form and a personal information form were used to measure the consumer approach to the use of organic ingredients in the production of organic products. Questionnaire forms were completed face-to-face in the city center between November 1 and December 30, 2019. The obtained data were analyzed with inferential and descriptive analysis.

Findings- One of the reasons why the demand for organic products is not as high as it should be is because consumers are sceptical of organic products' reliability, as well as the ingredients used. Consumers have a favourable attitude toward organic items. However, in this study, despite the positive evaluations for organic products, it was seen that there were question marks about the ingredients used and there was a dilemma. The participants were found to be unable to fully trust the definition of "organic product" or to be certain that organic products were free of synthetic raw materials, paraben, SLS, and other non-organic ingredients.

Conclusion- In Turkey and around the world, consumers' opinions regarding organic food products and their purchase behaviours, mostly on organic agricultural products, were investigated. What makes products organic are the ingredients used and the production methods. However, it is mentioned to directly explain what consumers think about organic ingredients with this study. The approaches of consumers regarding the ingredients of organic products within the framework of their socio-demographic characteristics is examined. In this context it has been discovered that consumer views on the use of organic ingredients in organic products vary depending on socio-demographic factors.
\end{abstract}

Keywords: Organic inputs, organic production, organic ingredient, organic consumption, consumer approach. JEL Codes: M30, M31, M39.

\section{INTRODUCTION}

Consumption has increased with social enrichment. To meet the increasing consumption needs, the number of products produced has also increased. Nevertheless, the number of ingredients used in production have increased drastically even though scientific, and technological innovations affect life positively. As well as to extend the durability and average life of products, a wide variety of complex ingredients are used in production all over the world to reduce production costs and increase production quantities. Parallel to the negative impacts of production ingredients on human resources have begun to be considered, and it has been recognized that the quality of a sustainable life is determined by the quality of a sustainable product. Producers and consumers in many nations, particularly in high-income countries, have begun to turn to organic products that do not disrupt the natural balance, pollute the environment, or harm human health. Organic products are those that are produced and processed without the use of genetic engineering, artificial and similar fertilizers, preservatives, colorants, additives, chemicals, polishing agents, or chemical packing materials. Promoting sustainable consumption depends on spreading awareness of the environmental impact of products, product quality and product safety, and concern for the health aspect of products, especially for developing countries, the demand for organic products has increased and new market opportunities have emerged. In line with this interest, organic products are an essential sustainable consumption option among product alternatives. Indeed, while turning to organic products, 
consumers chose a product based on whether it was made with safe ingredients (Eryilmaz et al., 2015: 200). The starting point of this study is the thoughts of consumers about the ingredients used in the production of organic products. In this direction, the aim of this study is to determine the consumer approach towards the use of organic ingredients in the production of organic products within the framework of socio-demographic variables. With this study, it is thought that there can be contributions to overcome by discovering an obstacle in front of organic consumption to eliminate the concerns of consumers about organic ingredients and thus to encourage the expansion of the organic product market in our country.

\section{THEORETICAL FRAMEWORK}

\subsection{Organic Production}

Following the industrial revolution, technological advancements highlighted the need to boost the number of products available to meet the demands of an expanding population. While achieving maximum output in such a production process, the ecological balance has been disrupted along with the product quality. Uncontrolled and high-dose applications in the production process have wreaked havoc on the environment and human health. As a result, not only consumers but also producers have become concerned about environmental degradation, the threat of depletion of natural resources, and epidemic diseases. Organic production, known for its environmental friendliness, is a method of achieving ecological balance and economic self-sufficiency (Ak, 2004: 490). In other words, organic production can be characterized as a system that uses methods that minimize harm to human health and the environment as much as possible and is supervised by authorized institutions at every stage of the production-consumption cycle. Organic production promotes the utilization of renewable resources, energy conservation, environmental protection, and resource conservation without the use of synthetic ingredients (Organic Produce Export Committee, 2002). Besides, organic products are classified into three categories based on their content: 100 percent organic, organic, and product created with organic elements. If all the ingredients in the finished product are organic, it is referred to as a "100\% organic product." The term "organic product" refers to a product that contains at least $95 \%$ organic ingredients. The remaining amount consists of inorganic substances in these products. And finally, a product is described as "manufactured with organic materials" if at least 70\% of the ingredients in the final product are organic (Kılıç et al., 2014: 43-44). In Turkey, the terms organic and ecological have the same meaning, and "organic" refers to any product that is generated in a controlled and verified manner without the use of chemical ingredients in production (Kılıç et al., 2014: 40). This understanding entails assessing and documenting the enterprise's, product's, and input's compliance with the law at various phases, such as production process, processing, and storage (Gök, 2008: 37-39). In Turkey, like others, has rules prohibiting the sale of products that do not have an organic product certificate (Arasl and Esen, 2008: 23). Ecocert, USDA, ICEA, Soil Association, BDiH, CosmeBio, and Control Association are the top organic certification bodies in the global market. Organic agricultural products and processed organic food products, organic livestock, and non-food organic products market are the four primary groups that the organic product market may be divided into. Nuts, dried fruits, dried vegetables, fresh vegetables and fruits, legumes, spices and medicinal plants, industrial plants, oilseeds, and grains are the most common organic agricultural products. Frozen fruits and vegetables, fruit juices and concentrates, and other agricultural products are examples of processed organic food products. Organic animal items include milk, meat, and eggs, whereas non-food organic products include wooden furniture, toilet paper, children's toys, cosmetic products, home textiles, leather shoes, and bags (Marangoz, 2008: 81-86; Kılıç et al., 2014: 40).

\subsection{Literature Review and Development of Research Hypotheses}

Organic products give consumers the option of ensuring a high quality of life in contrast to synthetic products, which destroy natural life and ecological balance while also posing a health risk to consumers. In this context, Steenkamp, and Van Trijp (1996) analyzed demand in European organic product markets and discovered that, because of the low growth in demand, the choice of buyer markets is influenced by the diversity of traditional production in international competition. Kristensen, Juhl and Ostergaard (2001) demonstrated the long-term survival strategies of products that are faced with market conditions and delivered through the formulation of various organic product supply chains from producers to retailers. Zanoli investigated consumer patterns in organic product quality issues (2004). Sylvander and Francois (2006) drew attention to the environmental and ethical concerns regarding organic products. In their investigations, Willer, Yussefi-Menzler, and Sorensen (2008) looked at the evolution of the world-leading European organic market. In a comparison of organic and traditional products, Gakobo and Jere (2016) looked at consumer concerns about the impacts of chemical accumulation in traditional food products. Mhlophe (2016) investigated the link between organic product storage conditions and consumer concerns about pesticides and nutrition. In their study on climate change issues, Xie et al. (2015) discovered that organic ingredients relate to the absence of synthetics such as pesticides and chemical-based fertilizers used in agriculture. Wier et al. (2008) found that because the ingredients of organic products are free of chemical ingredients, consumers show a higher interest in organic products than traditional products. Curl et al. (2013) looked at the demographic, socioeconomic, and living environment factors that influence organic product use. Sarıkaya (2007), in his field 
research on the factors affecting organic product consumption, determined that the organic product preferences of consumers vary according to their demographic characteristics. Davies et al. (1995) found that gender and family income have a role in consumers' organic product preferences, showing that women are more likely to prefer organic products than men, and people with higher incomes are more likely to choose organic products than those with lower incomes. Çelik (2013) discovered that organic product preferences fluctuate depending on gender, wealth, and education level in a study evaluating consumer purchase behaviour. Varoğlu and Turhan (2016) reported that the purchase of organic products by middle-aged and above consumers with high education and income levels is high in their study on determining consumer trends in organic products. In this setting, demographic characteristics are expected to indicate a considerable difference in consumer behaviour toward organic ingredients. Consumer value judgments in organic food belief were investigated by Lea and Worsley (2005), who discovered that consumers consume less organic food because they have restricted access to it and because it is expensive. Chan (1999) found a link between environmental awareness and a preference for organic products in a study of the ecological market segment in Hong Kong. When Laroche et al. (2001) looked at consumers willing to pay more for environmentally friendly products, they discovered that environmental awareness is the most important factor that consumers with a high level of education and a higher-than-average economic income consider when shopping for organic products. Sandalloğlu (2014) found that organic items are mostly purchased through markets and supermarkets in a study on the consumption of organic agricultural products in Adana. Inci, Karakaya and Şengül, (2017) investigated the effect of mass media on the consumers' knowledge about organic products in Diyarbakır. Naspetti and Zanoli (2009) explored consumers' awareness of how organic foods are produced and processed. In their study, Curl et al. (2013) discovered that social perceptions of organic products, socioeconomic characteristics, and individual characteristics all play a role in organic product consumption. In this perspective, demographic characteristics are expected to reflect a considerable difference in consumer behaviour toward organic ingredients. When current and new consumers look at the big picture, they want to know what is done to preserve and even strengthen organic standards in the industry, and what the standards are, according to the Organic Trade Association's (2015) "All Things Organic" conference, where the organic market and consumer trends are discussed. It is not necessary to make a special distinction between organic products for consumption in this study since it has been determined that there is little difference for the consumers between the organic products and non-food organic products, according to the study of Bozga (2015). It is also especially important to what extent consumers find reliable the information that the ingredients of products such as food, textile, cosmetics which are grown without the use of synthetic fertilizers, pesticides, and hormones, and processed without the use of synthetic chemicals, are organic. In this study, it is aimed to find answers to questions about the relative importance of organic ingredients in consumers' evaluations of organic products. Hypotheses have been constructed based on the survey questions prepared in this direction to ensure that consumers' opinions about organic ingredients are understood.

H1: According to the socio-demographic characteristics of the consumers, there is a statistically significant difference in their approaches on the use of organic ingredient in organic products.

$\mathrm{H} 1^{\mathrm{a}}$ : The opinion that organic ingredients are totally used in organic products (OIP) shows a statistically significant difference according to the socio-demographic characteristics of the consumers.

$\mathrm{H}_{1}{ }^{\text {b }}$ : The opinion that organic ingredients are not totally used in organic products (NOIP) shows a statistically significant difference according to the socio-demographic characteristics of the consumers.

\section{METHOD}

\subsection{The Purpose and Model of the Research}

This study aims to determine the relative approaches of the consumers towards the ingredients used in the production of organic products. It was attempted to examine whether consumer attitudes on the usage of organic ingredients in organic products differed based on sociodemographic variables. In this vein, the aim of this study is to examine the consumer approach towards the use of organic ingredients in the production of organic products according to sociodemographic variables. The perceptions that "organic ingredients are totally (\%95 and more) used" and that "organic ingredients is not totally (\%95 and more) used" in the production constitute the approaches of consumers towards the use of organic ingredients in the production of organic products. While consumers' approaches to the use of organic ingredients in organic products express the dependent variable; socio-demographic variables represent independent variables. The model of the study is to examine whether the approaches of consumers differ based on socio-demographic variables, according to OIP and NOIP. The predicted outcome of the study is that OIP and NOIP determine consumers' approaches to the use of organic ingredients in organic products (OIOP) and vary depending on socio-demographic factors. 


\subsection{Sampling and Data Collection Method}

When the studies on organic products and organic consumption are examined, it is obvious that women are more inquisitive about organic products than men and that they buy and consume more (Storstad and Bjorkhaug, 2003: 151-163; Curl et al., 2013: 769-778; Akn et al., 2010: 29-56). Women are more health conscious (Kemmer et al., 1998; Fagerli and Wandel, 1999) and are more concerned with their children and household responsibilities, according to research (Lockie et al., 2002). As a result, the study's primary focus is on women consumers residing in the Malatya province. According to 2019 figures, the province's female population is 401961 (TÜK, 2019). The study's sample size was determined using the simple random probability sampling method. In determining the sample size (n), " $p$ " represents the ratio of the sample to represent the population, "q (1-p)" represents the non-observation rate of the sample, "z $\alpha$ " represents the standard value corresponding to the confidence level (1.96 for $\alpha=0.05$ at $95 \%$ confidence level), and " $d$ " represents the accepted error tolerance level (which is determined as 0.05) (Arıkan, 2017: 308; Özdamar, 2003: 116-118). As a result of the calculations, $\left(p \times q \times z^{2} \alpha\right) \div d^{2}=384$ samples were determined. Although 650 samples were collected for this investigation, the pre-analysis exams determined that 608 samples were appropriate. The study's participant questionnaire forms were completed face-to-face in the city center between November 1 and December 30, 2019.

\subsection{Scale of the Study}

The survey form of the study consists of two parts. In the first part, the "Scale of the consumer approach to the use of organic ingredient in the production of organic products" (OIOP) was used. The scale used in this study to determine consumer attitudes toward the use of organic ingredients in the production of organic products is based on the "Perceived risk" scale used in Ness, Brennan, Oughton, Ritson, Ruto (2010) studies as well as the "Organic food beliefs" scale used in Dreezens, Martijn, Tenbult, Kok, Vries' study (2005). The participants were asked to mark the option they thought was acceptable with the expressions "strongly disagree, disagree, undecided, agree, totally agree" on a five-point Likert-type scale. In the factor analysis process, factor load values were examined in the process of assigning or removing scale items to factors. Nine items were eliminated from the 18 questions given to 110 participants in the pre-test as they did not meet the relevant factor. The participants were given a questionnaire form with nine questions in this direction. The OIOP approach was separated into two variables as a consequence of the analysis: With six questions, the first element is "the belief that organic ingredients are totally utilized in the manufacture of organic products," and the second element is "the belief that organic ingredients are not totally utilized in the creation of organic products." As a result, the scale was created to illustrate the OIOP approach. The normal distribution of kurtosis and skewness values obtained from within-item scales is between +3 and -3 (Kline, 2005; Brown, 2006; Aldrich, 2014). In the second section of the study, 12 questions based on Dreezens et al. (2005) are asked about the participants' socio-demographic characteristics. The relation between consumers' attitudes toward organic ingredients usage in organic products and their sociodemographic features has been investigated in this direction.

\subsection{Analysis and Evaluation of Data}

The data from the study were analyzed using the statistical package applications SPSS 21.0 and AMOS 21 . Validity and reliability are required for the data gathering instrument to achieve its goal (Spector, 1981: 37). As a result, the study's data gathering tool's validity and reliability were investigated. To determine whether the scale is suitable for factor analysis, the KMO and Bartlett's sphericity test (Punch, 2005; Kalaycl, 2010) were used. After determining the structure of the factors, the factor structure was tested with confirmatory factor analysis and the fit indices were calculated. As a result, the validity of the scales used in the study was confirmed through confirmatory factor analysis. Following this, parametric analysis approaches were employed to assess factor dimensions and participants based on sociodemographic variables. Therefore, the research's assumptions were proven correct at a 95\% confidence level.

\section{FINDINGS OF THE STUDY}

\subsection{Inferential Statistical Findings (EFA)}

After the Explanatory Factor Analysis (EFA) was performed to test the reliability of the measuring tool, Cronbach's Alpha internal consistency coefficient $(\alpha)$ value was determined as 749. The score ranges of the items in the Explanatory Factor Analysis, as well as the values that fall within these ranges, are shown in table 1. 
Table 1: Factor Analysis Results of Consumer Approach Towards the Use of Organic Ingredients in Organic Products (OIOP)

\begin{tabular}{|c|c|c|c|c|c|}
\hline Dimension & Items & Explanation & $\begin{array}{l}\text { Factor } \\
\text { Load }\end{array}$ & $\begin{array}{l}\text { Variance } \\
\text { Ratio }\end{array}$ & $\begin{array}{l}\text { Cronbach } \\
\text { 's Alpha }\end{array}$ \\
\hline \multirow{6}{*}{$\begin{array}{l}\text { The opinion that } \\
\text { organic } \\
\text { ingredients are } \\
\text { used totally (\%95 } \\
\text { and more) in the } \\
\text { manufacturing of } \\
\text { organic products } \\
\text { (OIP) }\end{array}$} & OIOP3 & $\begin{array}{l}\text { Ingredients such as raw materials and semi-processed } \\
\text { products used in the production of organic products do } \\
\text { not harm human health and nature. }\end{array}$ & .743 & \multirow{6}{*}{30.341} & \multirow{6}{*}{.749} \\
\hline & OIOP1 & $\begin{array}{l}\text { I believe that organic products are produced without } \\
\text { the use of chemicals and synthetic substances. }\end{array}$ & .731 & & \\
\hline & OIOP4 & $\begin{array}{l}\text { I believe that the ingredients used in the production of } \\
\text { non-organic products threaten human health, and I } \\
\text { support the use of organic products. }\end{array}$ & .708 & & \\
\hline & OIOP5 & $\begin{array}{l}\text { I support organic food production to protect future } \\
\text { generations and nature. }\end{array}$ & .613 & & \\
\hline & OIOP8 & $\begin{array}{l}\text { I believe that there are no paraben, SLS, etc., chemical } \\
\text { and synthetic ingredients in organic products. }\end{array}$ & .591 & & \\
\hline & OIOP9 & $\begin{array}{l}\text { I believe that only organic ingredients such as organic } \\
\text { raw materials and organic fertilizers are used in the } \\
\text { production of organic products. }\end{array}$ & .562 & & \\
\hline \multirow{3}{*}{$\begin{array}{l}\text { The opinion that } \\
\text { organic } \\
\text { ingredients are not } \\
\text { used totally (\%95 } \\
\text { and more) in the } \\
\text { manufacturing of } \\
\text { organic products } \\
\text { (NOIP) }\end{array}$} & OIOP6 & $\begin{array}{l}\text { I believe that inorganic ingredients are used in the } \\
\text { production of organic products as in the production of } \\
\text { classical products. }\end{array}$ & .846 & \multirow{3}{*}{22.338} & \multirow{3}{*}{.711} \\
\hline & OIOP2 & $\begin{array}{l}\text { I believe that chemicals are used in the production of } \\
\text { organic products. }\end{array}$ & .785 & & \\
\hline & OIOP7 & $\begin{array}{l}\text { I think that some inorganic raw materials are inevitably } \\
\text { used in the production of organic products. }\end{array}$ & .709 & & \\
\hline \multicolumn{4}{|l|}{ Total } & 52.679 & .721 \\
\hline \multicolumn{6}{|c|}{ Kaiser-Meyer-Olkin Test: 0.766} \\
\hline
\end{tabular}

In the analysis undertaken to assess the consumer attitude toward the use of organic ingredients in the manufacture of organic products, the KMO value was estimated as 0.766 . As a result, the sample size (KMO>0.500) is suitable for factor analysis. The $\chi 2$ value was found to be 1223.513 and statistically significant $(p<0.05)$ within the scope of the Bartlett test. The data were found to be suitable for factor analysis based on the results of the KMO and Bartlett tests (Bryant and Yarnold, 1995: 112). The scale was discovered to have two factors based on the results of a factor analysis performed to reduce many connected variables to a few significant and independent factors (Kalaycl, 2009: 321). The scale's first dimension, which represents the idea that organic ingredients are totally used in the manufacture of organic products, is made up of six items with factor loads ranging from 0.562 to 0.743 . The dimension's ratio of explaining total variance is 30,341 percent, with a reliability coefficient of 0.749 . The idea that organic ingredients are not totally utilized in the production of organic products is represented by the second dimension of the scale, which consists of three items with factor loads ranging from 0.709 to 0.846 . The ratio of the dimension to explain the total variance is 22.338 percent, while the reliability coefficient is 0.711 . As a result, $52.679 \%$ was calculated as the ratio of explaining the total variance of both dimensions. The scale is reliable, and the reliability coefficient for the consumer approach to the use of organic ingredients in the production of organic products (OIOP) was found to be 0.721 (Trierweiler, 2009).

\subsection{Inferential Statistical Findings (CFA)}

Confirmatory factor analysis (CFA) is a method of determining how well factors (latent variables) derived from a large number of variables and supported by a theoretical foundation fit the actual data (Sümer, 2000: 52). In other words, CFA aims to examine to what extent a predetermined or constructed structure is in compliance with the collected data. 
Table 2: CFA Findings Regarding the OIOP Approach

\begin{tabular}{|l|c|c|c|c|c|c|}
\hline Acceptable Fit Indices & X2/sd <5 & GFI $>0.90$ & AGFI $>0.90$ & CFI $>0.90$ & RMSEA $<0.08$ & RMR $<0.08$ \\
\hline Calculated Fit Indices & 5.710 & 0.949 & 0.905 & 0.901 & 0.097 & 0.084 \\
\hline
\end{tabular}

Acceptable levels of fit indices values are $(\chi 2 / \mathrm{sd}<5, \mathrm{GFI}>0.90, \mathrm{AGFI}>0.90, \mathrm{CFI}>0.90, \mathrm{RMSEA}<0.08, \mathrm{RMR} 0.08)$ (Wang and Wang, 2012). While it is seen that the GFI, AGFI, CFI fit indices calculated in the CFA analysis provide acceptable fit indices, it is seen in table 2 that $\chi 2 / s d, R M S E A$, and RMR indexes are close to and provide acceptable fit indices. In the factorial structure of the consumer approach scale towards the use of organic ingredients in organic products (OIOP), the two-factor measurement model was developed. OIP Dimension (the opinion that organic ingredients are totally used in organic products) and NOIP Dimension (the opinion that organic ingredients are not totally used in organic products). The covariance value (Kline, 2005), which shows the change of two variables relative to each other, was calculated as 0.22 , bidirectional between OIP and NOIP. When one of these two dimensions changes, the other changes by 0.22 . The bidirectional covariance values regarding the consumer approach to the use of organic ingredients in the production of organic products between the items were found to be as follows: between OIOP3 and OIOP1 items, cov (df / e2, df / e1) = 0.16; between OIOP4 and OIOP5 items, two-way cov (df / e4, df / e3) = 0.4; between the OIOP3 and OIOP9 items, negative two-way $\operatorname{cov}(\mathrm{df} / \mathrm{e} 6 \mathrm{df} / \mathrm{e} 1)=0.15$. As a result, a one-unit change in OIOP3's standard deviation produces a positive 0.16 change in OIOP1's standard deviation and a negative 0.15 change in OIOP9's standard deviation. A change in one of the items of OIOP5 and OIOP4 causes a change of 0.4 in the other. If the path coefficient value calculated in the confirmatory factor analysis roadmap is $>0.50$, this is considered a strong effect (Hatcher, 1994: 332). For all items in the CFA roadmap for the consumer approach to the use of organic ingredients in the production of organic goods, the road coefficients are more than 0.50 . The road coefficients were calculated as .67, .58, .59, .50, .51, .55, .83, .62, .58 for the items OIOP3, OIOP1, OIOP4, OIOP5, OIOP8, OIOP9, OIOP6, OIOP2, OIOP7 respectively, and the road coefficients were observed to be statistically significant. The OIOP6 item was found to have the most modifications among the fit indices. Confirmatory factor analysis was also utilized to confirm the validity of the scales employed in this study.

Table 3: Normality Test of Consumer Attitude Factors for the Use of Organic Ingredients in Organic Products

\begin{tabular}{llllllll}
\hline & $\mathbf{n}$ & Min. & Max. & Average & ss & Skewness & Kurtosis \\
\hline OIP Dimension & 608 & 1.00 & 5.00 & 3.53 & 0.67 & -.707 & 1.473 \\
NOIP Dimension & 608 & 1.00 & 5.00 & 3.42 & 0.84 & -.346 & -.054 \\
OIOP-Consumer Approach & 608 & 1.00 & 5.00 & 3.47 & 0.58 & -.617 & 2.008 \\
\hline
\end{tabular}

In statistical studies, it is desirable that the sample distribution be normal or close to normal (Curran et al., 1996: 17). Finney and DiStefano (2013) described \pm 2 interval for skewness and \pm 7 interval for kurtosis normal (Finney and DiStefano, 2013: 439; Muthén and Kaplan, 1985: 171). The data gathered in the study had a normal distribution, as shown in appe 3 . For this reason, parametric techniques (independent sample t-test, one-way analysis of variance) were utilized in the analysis conducted in the research (Kline, 2005).

\subsection{Descriptive Statistical Findings}

\subsubsection{Socio-Demographic Findings Regarding Participants}

It was found that 84.1 percent of the study's participants reside in a metropolitan area. After the province of Malatya became a metropolitan city in the 2014 local elections, it was found that 509 participants resided in the metropolitan city in terms of the settlement. Of the participants, $8.8 \%$ reside in the city and $7.1 \%$ of them in the county or village. The proportion of married participants is $54.4 \%$, whereas the rate of single participants is $45.5 \%$. Consumers between the ages of 18 and 26 make up $39.7 \%$ of the study's participants; consumers between the ages of 27 and 35 make up 25.4 percent; consumers between the ages of 36 and 44 make up 23.1 percent, and consumers aged 45 and above make up 11.8 percent. As a result, consumers aged 45 and under are the majority of those who participate in this study. The proportion of participants with undergraduate and graduate education is 46.7 percent, the proportion of participants with high school education is 33.3 percent, and the proportion of participants with primary education is $20 \%$. Students make up 28.5 percent of the participants, while housewives make up $38.8 \%$, employees make up $27.7 \%$, and retirees make up 2.9 percent. An average monthly income was discovered in 52.1 percent of the individuals with 
an income level between 2500 and 6500 TL. The proportion of those who had previously consumed or are continuing to consume organic items was determined to be $68.9 \%$ in the inquiry about whether the participants consumed organic items. This is an indication of the familiarity of organic products in Malatya province. It was also determined that $61.1 \%$ of consumers evaluated based on health awareness and found organic products beneficial for health. The percentage of individuals who said social impacts were the most important factor in their decision to buy organic products is 26.4 percent. The tendency of consumers in Malatya to consume organic products based on environmental awareness was $6.2 \%$, and the rate due to other factors (prices, campaigns, etc.) that they consider was $6.3 \%$. The percentage of participants who find organic products affordable is low (21.1\%), whereas the percentage of consumers who do not find them affordable is high (78.9\%). As a result, the idea that organic products are not cost-effective from the perspective of consumers persists. The percentage of persons who suggested organic items they had previously consumed or used to others they knew or did not know (people in close circles, friends, people they knew and didn't know on social media, etc.) was found to be as high as $88.7 \%$. The rate of respondents who answered "directly from the producer in Malatya" to the question of where they bought or can buy organic products was determined as $28.6 \%$. This rate was followed by 28 percent of participants who picked the grocery store chains option. The fact that organic items are sold in the aisles of grocery store chains in the province of Malatya and that 28 percent of consumers prefer this alternative demonstrates that consumers have faith in the province's grocery store chains when it comes to organic products. In the province of Malatya, it was discovered that $18.7 \%$ of participants prefer to buy organic products from the internet by using the websites of the producers, mostly e-commerce sites in the role of distributors, when they are unable to obtain the product, they desire or cannot find in grocery store chains. The remaining 24.7 percent of interviewees chose other local retailers, which were expressed as bazaars. The ratio of the participants who spend up to $200 \mathrm{TL}$ per month on organic products is $63.5 \%$. Consumers who spent $201-500 \mathrm{TL}$ on organic items every month made up 20.1 percent, while 9.1 percent spent more than $500 \mathrm{TL}$, and 7.3 percent did not spend at all. It can be argued by looking at these rates that consumers in Malatya province spend on organic products in one way or another. In general, the demographic characteristics of the participants are regarded to provide adequate and healthy data for evaluating the study's findings.

\subsubsection{Participant Findings on OIOP Approach}

To determine the evaluations of the consumers participating in the research on the use of organic ingredients in the production of organic products, table 4 shows the average and percentage distributions of consumers showing their level of agreement with the statements of the OIOP approach.

Table 4: Levels and Average of Consumers' Agreement in Statements of the OIOP Approach

\begin{tabular}{|c|c|c|c|c|c|c|c|c|c|c|c|}
\hline \multirow[b]{3}{*}{ Items } & \multicolumn{4}{|c|}{ Strongly } & \multirow{2}{*}{\multicolumn{2}{|c|}{ Undecided }} & \multirow{2}{*}{\multicolumn{2}{|c|}{ Agree }} & \multirow{2}{*}{\multicolumn{2}{|c|}{ Totally Agree }} & \multirow[b]{3}{*}{ Average } \\
\hline & \multicolumn{2}{|c|}{ Disagree } & \multicolumn{2}{|c|}{ Disagree } & & & & & & & \\
\hline & $\mathbf{n}$ & $\%$ & $\mathbf{n}$ & $\%$ & $\mathbf{n}$ & $\%$ & $\mathbf{n}$ & $\%$ & $\mathrm{n}$ & $\%$ & \\
\hline OIOP1 & 72 & 11.8 & 81 & 13.3 & 244 & 40.1 & 151 & 24.8 & 60 & 9.9 & 3.08 \\
\hline OIOP2 & 48 & 7.9 & 87 & 14.3 & 217 & 35.7 & 187 & 30.8 & 69 & 11.3 & 3.23 \\
\hline OIOP3 & 35 & 5.8 & 66 & 10.9 & 208 & 34.2 & 223 & 36.7 & 76 & 12.5 & 3.39 \\
\hline OIOP4 & 26 & 4.3 & 53 & 8.7 & 100 & 16.4 & 321 & 52.8 & 108 & 17.8 & 3.71 \\
\hline OIOP5 & 19 & 3.1 & 24 & 3.9 & 57 & 9.4 & 250 & 41.1 & 258 & 42.4 & 4.16 \\
\hline OIOP6 & 38 & 6.3 & 62 & 10.2 & 209 & 34.4 & 203 & 33.4 & 96 & 15.8 & 3.42 \\
\hline OIOP7 & 28 & 4.6 & 51 & 8.4 & 154 & 25.3 & 276 & 45.4 & 99 & 16.3 & 3.60 \\
\hline OIOP8 & 38 & 6.3 & 62 & 10.2 & 257 & 42.3 & 182 & 29.9 & 69 & 11.3 & 3.30 \\
\hline OIOP9 & 19 & 3.1 & 40 & 6.6 & 228 & 37.5 & 243 & 40.0 & 78 & 12.8 & 3.53 \\
\hline
\end{tabular}

Within the framework of the questions addressed to the consumers participating in the research, the answers given to the items that help explain the dimensions of the study were examined. As a result, the following are the assertions that consumers most usually agree with in this study:

- "I believe that the development of organic products should be encouraged in order to safeguard future generations and the environment." 
- "I think that the ingredients used in the production of non-organic products threaten human health and I support the preference of organic products."

- These are the expressions that have the highest average level of consumer agreement. In this regard, it may well be claimed that the consumers who took part in this study have favorable attitudes toward organic products. Following these two statements, it can be concluded that the high level of agreement among consumers with the statement "I believe that some non-organic raw materials are inevitably used in the production of organic products" reveals that, despite consumers' positive opinions of organic products, there are concerns about the ingredients used. The statements that consumers did not agree with in this study are as follows:

- "I believe that organic products are produced without the use of chemicals."

- "I believe that chemicals are used in the production of organic products."

These are the expressions that have the lowest average level of consumer agreement. It was determined that 25.1 percent of consumers disagreed that organic items were manufactured without the use of chemicals, while 22.2 percent disagreed that they were made using chemical ingredients. Consumers cannot fully accept the notion of "organic product" in their minds, as seen by these expressions, and are unclear whether organic products are chemical-free. The statement that the consumers were most undecided about in this study is "I think that there is no paraben, SLS, etc. chemical ingredients in organic products". In this regard, it was discovered in this study that consumers were unable to make a clear judgment and were uncertain in their evaluation due to a lack of belief in the necessity of producing organic products using organic ingredients.

In terms of the variables of the place where the participants live, the OIOP approaches were examined, and the results of the oneway variance test findings are presented in table 5.

Table 5: Examination of Consumers' OIOP Approaches in Terms of Where They Live

\begin{tabular}{|c|c|c|c|c|c|c|}
\hline & Location & $\mathbf{n}$ & Average & sd & $\mathbf{F}$ & $\mathbf{p}$ \\
\hline & Metropolis & 509 & 3.52 & 0.66 & & \\
\hline \multirow[t]{3}{*}{ OIP Dimension } & City & 53 & 3.42 & 0.73 & 1.542 & .215 \\
\hline & County/Village & 43 & 3.66 & 0.61 & & \\
\hline & Metropolis & 509 & 3.42 & 0.82 & & \\
\hline \multirow[t]{3}{*}{ NOIP Dimension } & City & 53 & 3.36 & 0.92 & 0.176 & .839 \\
\hline & County/Village & 43 & 3.47 & 0.93 & & \\
\hline & Metropolis & 509 & 3.47 & 0.57 & & \\
\hline \multirow[t]{2}{*}{ OIOP Consumer Approach } & City & 53 & 3.39 & 0.70 & 1.028 & .359 \\
\hline & County/Village & 43 & 3.56 & 0.58 & & \\
\hline
\end{tabular}

$* p<0.05$

According to the data acquired, there is no statistically significant difference in terms of OIOP with the conclusions that organic ingredients are used or not used in the production ( $p>0.05)$. The findings of this study shows that consumers' attitudes on the use of organic ingredients are not affected by their geographic location.

The ANOVA test findings of the OIOP approaches in terms of the age variable of the participants are given in Table 6.

Table 6: Age Analysis of Consumers' OIOP Approaches

\begin{tabular}{|c|c|c|c|c|c|c|c|c|}
\hline & Age & & $\mathbf{n}$ & Average & sd & $\mathbf{F}$ & $\mathbf{p}$ & $\begin{array}{l}\text { Multiple } \\
\text { Comparison }\end{array}$ \\
\hline \multirow{4}{*}{ OIP Dimension } & $18-26$ & & 239 & 3.47 & 0.69 & \multirow{4}{*}{$\begin{array}{l}3.30 \\
4\end{array}$} & \multirow{4}{*}{$\begin{array}{l}.020 \\
*\end{array}$} & $2>4$ \\
\hline & $27-35$ & & 153 & 3.63 & 0.54 & & & \\
\hline & $36-44$ & & 139 & 3.56 & 0.68 & & & \\
\hline & $\begin{array}{l}45 \\
\text { above }\end{array}$ & and & 71 & 3.37 & 0.77 & & & \\
\hline NOIP Dimension & $18-26$ & & 239 & 3.38 & 0.85 & & .463 & \\
\hline
\end{tabular}




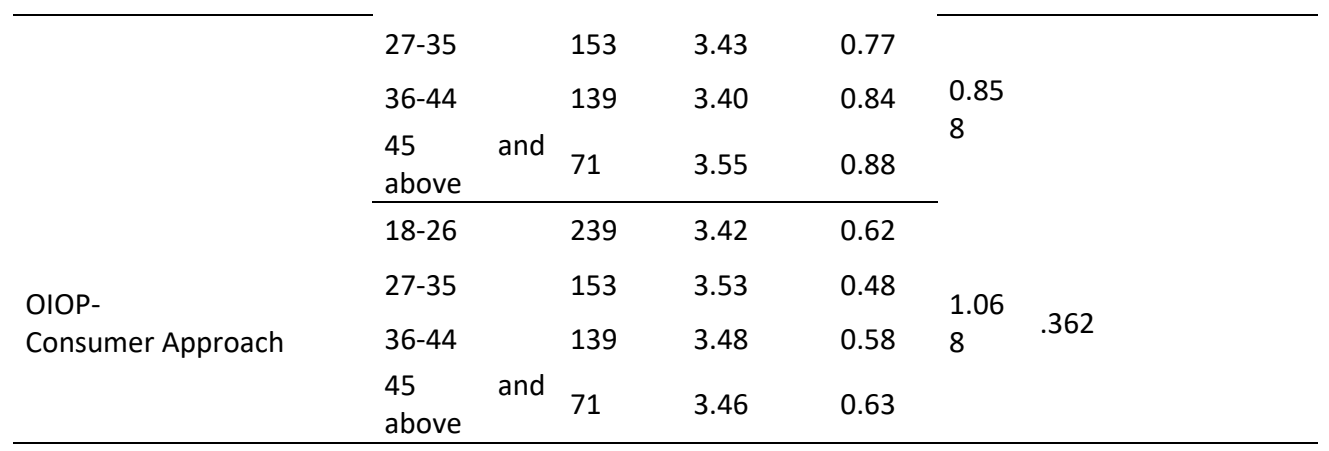

$* p<0,05$

There is no statistically significant difference in the opinion of consumers of different ages that organic ingredients are not used in the production of organic products $(p>0.05)$. However, based on the age variable, there is a statistically significant difference in the belief that organic ingredients are totally used in the production of organic products $(p<0.05)$. As a result, it was discovered that consumers aged 27-35 perceived organic product ingredients to be more reliable compared to consumers aged 45 and over. Based on the findings, it was discovered that the OIOP consumer approach did not change statistically depending on age ( $p>0.05)$.

The t-test findings of the OIOP consumer approaches based on the marital status variable of the participants are given in Table 7.

Table 7: Examination of Consumers' OIOP Based on Marital Status

\begin{tabular}{lllllll}
\hline & Marital Status & $\mathbf{n}$ & Average & sd & $\mathbf{t}$ & $\mathbf{p}$ \\
\hline \multirow{2}{*}{ OIP Dimension } & Single & 275 & 3.49 & 0.66 & & \\
& Married & 330 & 3.56 & 0.68 & -1.399 & .162 \\
NOIP Dimension & Single & 275 & 3.49 & 0.82 & & \\
\multirow{2}{*}{ OIOP- } & Married & 330 & 3.36 & 0.85 & & .017 \\
Consumer Approach & Single & 275 & 3.49 & 0.60 & & \\
& Married & 330 & 3.46 & 0.57 & 0.571 & .568 \\
\hline
\end{tabular}

$* p<0,05$

According to the findings, there is no statistically significant difference in consumers' marital status between the OIP, NOIP and OIOP approaches $(p>0.05)$. According to the study findings, the approach does not alter depending on whether the consumers are married or single.

The one-way variance test findings of the OIOP approaches based on the educational status of the participants are given in Table 8.

Table 8: Examination of Consumers' OIOP Approaches Based on Educational Status

\begin{tabular}{lllllll}
\hline & Educational Status & $\mathbf{n}$ & Average & sd & F & p \\
\hline \multirow{3}{*}{ OIP Dimension } & Primary School & 119 & 3.60 & 0.67 & & \\
& High School & 198 & 3.51 & 0.72 & & \\
& University & 248 & 3.49 & 0.56 & 1.392 & .244 \\
& Master's/PhD & 29 & 3.33 & 0.97 & & \\
degrees & Primary School & 119 & 3.36 & 0.96 & & \\
\cline { 2 - 5 } NOIP Dimension & High School & 198 & 3.47 & 0.88 & 0.571 & .634 \\
& University & 248 & 3.44 & 0.71 & & \\
\hline
\end{tabular}




\begin{tabular}{llllll}
\hline & $\begin{array}{l}\text { Master's/PhD } \\
\text { degrees }\end{array}$ & 29 & 3.33 & 0.79 & \\
\cline { 2 - 5 } & Primary School & 119 & 3.48 & 0.59 & \\
OIOP- & High School & 198 & 3.49 & 0.66 & \\
Consumer Approach & $\begin{array}{l}\text { University } \\
\text { Master's/PhD }\end{array}$ & 248 & 3.47 & 0.49 & $0.636 \quad .592$ \\
& degrees & 29 & 3.33 & 0.68 \\
\hline
\end{tabular}

$* p<0,05$

There is no statistically significant difference in the consumer approach of OIP, NOIP and OIOP based on the educational status variable ( $p>0.05)$. Consumers' opinion on the use of organic ingredients have been found to be unaffected by education level.

The ANOVA test findings of the OIOP approaches based on the vocation variable of the participants are given in Table 9.

Table 9: Analysis of Consumers' OIOP Approaches Based on Vocation

\begin{tabular}{|c|c|c|c|c|c|c|}
\hline & Vocation & $\mathbf{n}$ & Average & sd & $\mathbf{F}$ & $\mathbf{p}$ \\
\hline \multirow{8}{*}{ OIP Dimension } & Worker & 27 & 3.30 & 0.95 & \multirow{8}{*}{1.682} & \multirow{8}{*}{.111} \\
\hline & Official & 56 & 3.71 & 0.49 & & \\
\hline & Retired & 17 & 3.64 & 0.55 & & \\
\hline & Housewife & 226 & 3.51 & 0.67 & & \\
\hline & Self-employed & 10 & 3.50 & 1.09 & & \\
\hline & Student & 166 & 3.47 & 0.66 & & \\
\hline & Jobless & 29 & 3.48 & 0.54 & & \\
\hline & Employed in private sector & 49 & 3.68 & 0.73 & & \\
\hline \multirow{8}{*}{ NOIP Dimension } & Worker & 27 & 3.40 & 0.70 & \multirow{8}{*}{0.433} & \multirow{8}{*}{.882} \\
\hline & Official & 56 & 3.27 & 0.62 & & \\
\hline & Retired & 17 & 3.45 & 0.97 & & \\
\hline & Housewife & 226 & 3.40 & 0.91 & & \\
\hline & Self-employed & 10 & 3.43 & 1.03 & & \\
\hline & Student & 166 & 3.43 & 0.83 & & \\
\hline & Jobless & 29 & 3.53 & 0.69 & & \\
\hline & Employed in private sector & 49 & 3.52 & 0.89 & & \\
\hline \multirow{8}{*}{ OIOP-Consumer Approach } & Worker & 27 & 3.35 & 0.70 & \multirow{8}{*}{0.636} & \multirow{8}{*}{.726} \\
\hline & Official & 56 & 3.49 & 0.40 & & \\
\hline & Retired & 17 & 3.54 & 0.41 & & \\
\hline & Housewife & 226 & 3.46 & 0.59 & & \\
\hline & Self-employed & 10 & 3.47 & 1.00 & & \\
\hline & Student & 166 & 3.45 & 0.61 & & \\
\hline & Jobless & 29 & 3.51 & 0.46 & & \\
\hline & Employed in private sector & 49 & 3.60 & 0.59 & & \\
\hline
\end{tabular}

$* p<0,05$

There is no statistically significant difference in OIP, NOIP and OIOP approaches of consumers with different vocations ( $p>0.05$ ). Based on these data, it was discovered that consumer views were unaffected by their occupations. 
The ANOVA test findings of the OIOP approaches based on the household average monthly income variable of the participants are given in Table 10.

Table 10: Analysis of Consumers' OIOP Approaches Based on Household Average Monthly Income

\begin{tabular}{|c|c|c|c|c|c|c|}
\hline & Average Monthly Income & $\mathbf{n}$ & Average & sd & $\mathbf{F}$ & $\mathbf{p}$ \\
\hline \multirow{4}{*}{ OIP Dimension } & less than $2500 \mathrm{TL}$ & 221 & 3.50 & 0.73 & \multirow{5}{*}{.215} & \multirow{5}{*}{.930} \\
\hline & $2500-4500 \mathrm{TL}$ & 236 & 3.55 & 0.66 & & \\
\hline & $4501-6500 \mathrm{TL}$ & 78 & 3.54 & 0.62 & & \\
\hline & $6501-8500 \mathrm{TL}$ & 30 & 3.52 & 0.54 & & \\
\hline \multirow{6}{*}{ NOIP Dimension } & 8501 TL and above & 26 & 3.58 & 0.51 & & \\
\hline & less than $2500 \mathrm{TL}$ & 221 & 3.40 & 0.90 & \multirow{5}{*}{.666} & \multirow{5}{*}{.616} \\
\hline & $2500-4500 \mathrm{TL}$ & 236 & 3.40 & 0.84 & & \\
\hline & $4501-6500 \mathrm{TL}$ & 78 & 3.56 & 0.77 & & \\
\hline & $6501-8500 \mathrm{TL}$ & 30 & 3.48 & 0.71 & & \\
\hline & $8501 \mathrm{TL}$ and above & 26 & 3.36 & 0.67 & & \\
\hline \multirow{5}{*}{$\begin{array}{l}\text { OIOP- } \\
\text { Approach }\end{array}$} & less than $2500 \mathrm{TL}$ & 221 & 3.45 & 0.63 & \multirow{5}{*}{.455} & \multirow{5}{*}{.769} \\
\hline & $2500-4500 \mathrm{TL}$ & 236 & 3.47 & 0.58 & & \\
\hline & $4501-6500 \mathrm{TL}$ & 78 & 3.55 & 0.51 & & \\
\hline & $6501-8500 \mathrm{TL}$ & 30 & 3.50 & 0.42 & & \\
\hline & $8501 \mathrm{TL}$ and above & 26 & 3.47 & 0.43 & & \\
\hline
\end{tabular}

$* p<0,05$

When the average monthly income of the household was evaluated, it was shown that there was no statistically significant difference between the consumers' OIP, NOIP and OIOP approaches ( $p>0.05)$. The approach to the use of organic ingredients does not alter as per the average monthly income of consumer households, according to the study findings.

The t-test findings of the OIOP approaches based on the participants' consumption of organic products are given in Table 11.

Table 11: Analysis of Consumers' OIOP Approaches Based on Consumption of Organic Products

\begin{tabular}{lllllll}
\hline \multicolumn{2}{c}{ Do you consume organic products? } & $\mathbf{n}$ & Average & sd & $\mathbf{t}$ & $\mathbf{p}$ \\
\hline \multirow{2}{*}{ OIP Dimension } & Yes & 410 & 3.55 & 0.67 & & \\
& No & 185 & 3.49 & 0.66 & & .274 \\
\multirow{2}{*}{ NOIP Dimension } & Yes & 410 & 3.40 & 0.84 & & \\
& No & 185 & 3.47 & 0.84 & & .344 \\
OIOP-Consumer Approach & Yes & 410 & 3.48 & 0.58 & & \\
& No & 185 & 3.48 & 0.59 & & \\
\hline
\end{tabular}

$* p<0,05$

Based on the findings of the t-test ( $p>0.05)$, it was determined that there was no statistically significant difference. It has been determined that whether consumers use organic products does not make a difference in their thoughts about the ingredients of organic products.

Based on whether the participants find organic products economical or not, the t-test findings of the OIOP approaches are given in Table 12. 
Table 12: Analysis of Consumers' OIOP Approaches whether they find organic products economical or not.

\begin{tabular}{llllllll}
\hline $\begin{array}{l}\text { Do you find organic products } \\
\text { economical? }\end{array}$ & $\mathbf{n}$ & Average & sd & $\mathbf{t}$ & $\mathbf{p}$ & $\begin{array}{l}\text { Multiple } \\
\text { Comparison }\end{array}$ \\
\hline OIP Dimension & Yes & 127 & 3.60 & 0.83 & 1.386 & .166 & \\
& No & 475 & 3.51 & 0.62 & & & \\
NOIP Dimension & Yes & 127 & 3.27 & 0.98 & & & \\
& No & 475 & 3.46 & 0.79 & & & $2>1$ \\
OIOP- & Yes & 127 & 3.44 & 0.74 & -0.812 & .417 & \\
Consumer Approach & No & 475 & 3.49 & 0.53 & & & \\
\hline
\end{tabular}

$* p<0,05$

According to research, it has been determined that $78.9 \%$ of consumers do not find organic products economical. No statistically significant difference in terms of OIP and consumers finding organic products economical ( $p>0.05)$. However, there is a statistically significant difference between the consumers' thought of NOIP and the opinion that organic products are economical ( $p<0.05$ ). Accordingly, it has been determined that the approaches of consumers who are NOIP but do not find organic products economical are more positive than those who find it economical. However, in the overall analysis, it was also discovered that consumer approaches to the use of organic ingredients did not differ statistically significantly in terms of finding organic products economical $(p>0.05)$.

The t-test results of the participants' OIOP approaches based on suggesting organic goods to others (that they had previously consumed or are now consuming) is illustrated in Table 13.

Table 13: Analysis of Consumers' OIOP Approaches Based on Recommending Organic Products to Others

\begin{tabular}{llllllll}
\hline $\begin{array}{l}\text { Would you advise others of the } \\
\text { organic products you use? }\end{array}$ & $\mathbf{n}$ & Average & $\mathbf{s d}$ & $\mathbf{t}$ & $\mathbf{p}$ & $\begin{array}{l}\text { Multiple } \\
\text { Comparison }\end{array}$ \\
\hline OIP Dimension & Yes & 508 & 3.59 & 0.62 & 5.81 & $.000^{*}$ & $1>2$ \\
& No & 65 & 3.09 & 0.83 & 9 & & \\
NOIP Dimension & Yes & 508 & 3.43 & 0.81 & 1.64 & .101 & \\
& No & 65 & 3.25 & 1.02 & 5 & & $1>2$ \\
OIOP- & Yes & 508 & 3.51 & 0.54 & 4.52 & $.000^{*}$ & \\
Consumer Approach & No & 65 & 3.17 & 0.77 & 8 & & \\
\hline
\end{tabular}

$* p<0,05$

It has been revealed that $88.7 \%$ of consumers recommend to the others about organic products that they have consumed or currently consuming. Consumers' intention of recommending organic products to friends or strangers, differ statistically significantly as well as their OIP approach $(p<0.05)$. It has been determined that consumers who recommend organic products to the others have more positive opinion compared to those who do not. However, the NOIP approach does not display a statistically significant difference $(p>0.05)$. In the general evaluation, there is a statistically significant difference in the approach of OIOP in terms of consumers' recommendation of organic products to other consumers $(p<0.05)$. It has been discovered that consumers who recommend organic products to others have a more favourable attitude toward the use of organic ingredients in organic products than consumers who do not.

Table 14 shows the results of the one-way Anova test used to evaluate the OIOP approaches based on the amount of money spent on organic products each month by the participants. 
Table 14: Analysis of Consumers' OIOP Approaches Based on Monthly Money Spent for Organic Products

\begin{tabular}{|c|c|c|c|c|c|c|c|}
\hline \multicolumn{2}{|c|}{ Money spent monthly } & \multirow{2}{*}{$\begin{array}{l}n \\
42\end{array}$} & \multirow{2}{*}{$\begin{array}{l}\text { Average } \\
3.24\end{array}$} & \multirow{2}{*}{$\begin{array}{l}\text { sd } \\
0.61\end{array}$} & \multirow[t]{2}{*}{$\mathbf{F}$} & \multirow[t]{2}{*}{$\mathbf{p}$} & \multirow{2}{*}{$\begin{array}{l}\text { Multiple } \\
\text { Comparisor } \\
1<2\end{array}$} \\
\hline \multirow{4}{*}{ OIP Dimension } & 0 & & & & & & \\
\hline & $1-200$ & 366 & 3.57 & 0.65 & \multirow{3}{*}{3.901} & \multirow{3}{*}{$.009 *$} & \\
\hline & $201-500$ & 116 & 3.56 & 0.72 & & & $1<3$ \\
\hline & 501 and above & 52 & 3.41 & 0.69 & & & \\
\hline \multirow{4}{*}{ NOIP Dimension } & 0 & 42 & 3.27 & 0.74 & \multirow{4}{*}{4.118} & \multirow{4}{*}{$.007 *$} & \\
\hline & $1-200$ & 366 & 3.48 & 0.83 & & & $2>3$ \\
\hline & $201-500$ & 116 & 3.21 & 0.88 & & & \\
\hline & 501 and above & 52 & 3.55 & 0.87 & & & \\
\hline \multirow{4}{*}{$\begin{array}{l}\text { OIOP- } \\
\text { Consumer } \\
\text { Approach }\end{array}$} & 0 & 42 & 3.25 & 0.57 & \multirow{4}{*}{4.133} & \multirow{4}{*}{$.006 *$} & $1<2$ \\
\hline & $1-200$ & 366 & 3.53 & 0.55 & & & \\
\hline & $201-500$ & 116 & 3.38 & 0.66 & & & $3<4$ \\
\hline & 501 and above & 52 & 3.48 & 0.57 & & & \\
\hline
\end{tabular}

$*_{p}<0,05$

In this study, it was discovered that 20.1 percent of consumers spend 200-501 TL on organic goods per month, 9.1 percent spend $501 \mathrm{TL}$ and above, 63.5 percent spend 1-200 TL, and 7.3 percent do not spend any money. It has been observed that there is a statistically significant difference in terms of the belief that organic ingredients are used in the production of organic products by the consumers, whose monthly spending on organic products is different $(p<0.05)$. Accordingly, those who spend between 1 and 200 TL have a more optimistic opinion compared to those who do not spend at all; and those who spend between 201-500 TL have a more optimistic opinion than those who spend $501 \mathrm{TL}$ and more. It was discovered that there is a statistically significant difference in the opinion of NOIP among consumers with varying monthly expenditure on organic products $(p<0.05)$. As a result, individuals who spend between $501 \mathrm{TL}$ and more and 1-200 TL are more likely to believe that organic ingredients are not used in organic products than those who spend between 201 and $500 \mathrm{TL}$. It was discovered that consumers with varying monthly spending on organic products have statistically significant differences on OIOP approach $(p<0,05)$. Accordingly, those who spend between 1 and 200 TL have a more positive approach compared to those who do not spend at all; and those who spend 501 TL and more, have positive approach than those who spend between 201-500 TL.

The results of the Anova test, which was used to look at the fundamental aspects that participants evaluate while shopping for organic products in terms of OIOP approaches is shown in Table 15.

Table 15: Analysis of Consumers' OIOP Approaches in Terms of the Fundamental Aspects Considering in Organic Shopping Preferences

\begin{tabular}{|c|c|c|c|c|c|c|c|}
\hline & & $\mathbf{n}$ & Average & sd & $\mathbf{F}$ & $\mathbf{p}$ & $\begin{array}{l}\text { Multiple } \\
\text { Comparison }\end{array}$ \\
\hline \multirow{4}{*}{ OIP Dimension } & Social effects & 154 & 3.43 & 0.66 & \multirow{4}{*}{4.867} & \multirow{4}{*}{$.002 *$} & \multirow{5}{*}{$3>2$} \\
\hline & $\begin{array}{l}\text { Environmental } \\
\text { Awareness }\end{array}$ & 36 & 3.33 & 0.67 & & & \\
\hline & Health awareness & 356 & 3.62 & 0.64 & & & \\
\hline & Other & 37 & 3.39 & 0.83 & & & \\
\hline \multirow{4}{*}{ NOIP Dimension } & Social effects & 154 & 3.32 & 0.77 & \multirow{4}{*}{3.218} & \multirow{4}{*}{$.022 *$} & \\
\hline & $\begin{array}{l}\text { Environmental } \\
\text { Awareness }\end{array}$ & 36 & 3.13 & 0.84 & & & \multirow[t]{5}{*}{$2<3$} \\
\hline & Health awareness & 356 & 3.50 & 0.84 & & & \\
\hline & Other & 37 & 3.37 & 0.96 & & & \\
\hline OIOP- & Social effects & 154 & 3.38 & 0.58 & \multirow[b]{2}{*}{6.530} & \multirow[b]{2}{*}{$.000 *$} & \\
\hline $\begin{array}{l}\text { Consumer } \\
\text { Approach }\end{array}$ & $\begin{array}{l}\text { Environmental } \\
\text { Awareness }\end{array}$ & 36 & 3.23 & 0.48 & & & \\
\hline
\end{tabular}




\begin{tabular}{lllll}
\hline Health awareness & 356 & 3.56 & 0.56 & $3>2$ \\
Other & 37 & 3.38 & 0.71 & \\
\hline
\end{tabular}

$* p<0.05$

Consumers prefer organic products for a variety of reasons, the most common of which are health concerns, followed by social concerns and environmental concerns, with very few opting for organic products for reasons other than these. According to the basic factors they consider in the choice of organic product shopping, the ANOVA test revealed that there is a statistically significant difference in the opinion of OIP $(p<0.05)$. This difference has been discovered to be related to the fact that consumers who buy organic products for health reasons are more optimistic than those who buy organic products for environmental reasons. According to the basic factors they consider in the choice of organic product shopping, there is a statistically significant difference in the opinion of NOIP ( $<0.05$ ). This disparity has been discovered to be attributable to the fact that consumers who shop for organic items out of concern for the environment have more negative thoughts than consumers who shop for organic items out of concern for their health. It was determined that there is a statistically significant difference in terms of OIOP approaches of consumers according to the basic factors they consider in the choice of organic product shopping $(p<0.05)$. Consumers who prefer organic products because of health concerns have a more positive approach than those who shop for organic products because of environmental concerns.

The ANOVA test conducted to analyse the OIOP approaches based on the location where the participants buy organic products is given in Table 16.

Table 16: Analysis of OIOP Approaches of Consumers Based on the Location Organic Products Purchased

\begin{tabular}{lllllll}
\hline & & $\mathbf{n}$ & Average & sd & $\mathbf{F}$ & $\mathbf{p}$ \\
\hline \multirow{3}{*}{ OIP Dimension } & Supermarket & 163 & 3.49 & 0.68 & & \\
& Bazaar & 144 & 3.47 & 0.62 & & \\
& Internet & 109 & 3.63 & 0.62 & .537 & .204 \\
& Directly from producer & 167 & 3.56 & 0.73 & & \\
NOIP Dimension & Supermarket & 163 & 3.43 & 0.89 & & \\
& Bazaar & 144 & 3.40 & 0.80 & \multirow{2}{*}{0.118} & .950 \\
& Internet & 109 & 3.39 & 0.82 & & \\
OIOP- & Directly from producer & 167 & 3.44 & 0.83 & & \\
Consumer Approach & Supermarket & 163 & 3.46 & 0.64 & & \\
& Bazaar & 144 & 3.43 & 0.54 & \multirow{2}{*}{0.501} & .681 \\
& Internet & 109 & 3.51 & 0.56 & & \\
\hline
\end{tabular}

$* p<0,05$

Retail chains, specialized stores, neighborhood bazaars, wholesalers, producers selling through retailers directly or online are the main sales locations for organic products. Organic products are mostly purchased directly from the producer and from the market, according to research. Consumers' OIP and NOIP approaches in terms of where they buy organic products did not show statistically significant differences $(p>0.05)$. As a result, it has been discovered that consumers' OIOP approaches do not differ in terms of where they purchase organic products $(p>0.05)$

\section{DISCUSSION AND CONCLUSION}

In Turkey, the demand for organic products is insufficient. The reasons for this include, inaccurate or incomplete information, overly high product costs relative to income, a lack of consumer awareness, and insufficient use of marketing mix elements (Kaya, 2003). Low production hinders organic products from becoming widely available, while a lack of perceived value reduces the desire for organic products on the other hand (Honkanen et al., 2006). One of the reasons why the demand for organic products is not as high as it should be is because consumers are sceptical of organic products' reliability, as well as the ingredients used. In this study, consumers' attitudes toward the use of organic ingredients in use of organic products are explored in the context of their socio-demographic features. In addition to having a local or regional identity, organic products that can respond to changes in the organic structure with the product assurance label, where the specific features of the products are protected with the 
measures created for artificial ingredients. By this study it has been determined that organic products are supported by consumers. It has been discovered that consumers have a favourable attitude toward organic items. However, in this study, despite the positive evaluations for organic products, it was seen that there were question marks about the ingredients used and there was a dilemma. The participants were found to be unable to fully trust the definition of "organic product" or to be certain that organic products were free of synthetic raw materials, paraben, SLS, and other non-organic ingredients. Demographic characteristics play a role in consumers' opinions and purchasing behaviours toward organic products, according to studies (Radman, 2005; Ustaahmetoğlu and Toklu, 2015; Varoğlu and Turhan, 2016; Bahşi and Akça, 2019: Curl et al. 2013). However, it was concluded in this study that the consumers who took part in the survey did not differ in their attitudes toward the use of organic ingredients in organic goods solely because of demographic factors. This study discovered that whether consumers utilize organic products has no bearing on their views on the ingredients used in organic products. In addition to Lea and Worsley's (2005) finding that consumers consume fewer organic products because they are not cost-effective, this study found that consumers who believe that organic products are not used in organic products and do not find organic products cost-effective have more positive attitudes than those who find organic products economical. To increase the level of knowledge Naspetti and Zanoli (2009) emphasized the need to transfer production processes to consumers while Inci, Karakaya and Şengül (2017) pointed out the role of mass media in consumers' acquisition of information. Consumers' tendency to share information with one another can also have a positive impact. According to this, it has been found that consumers who recommend organic products that they consume to others have a more positive approach towards the use of organic ingredients in organic products than those who do not. It has been found that those who spend between 1 and 200 TL per month on organic products have a stronger positive opinion that organic ingredients are used in organic products than those who do not spend at all. Again, it was found that those who spend between 201-500 TL on organic products have a stronger positive opinion that organic ingredients are used in organic products than those who spend 501 TL or more. Furthermore, individuals who spend between 501 TL and more and 1-200 TL are more inclined to believe that organic ingredients are not used in organic products than those who spend between 201 and 500 TL. It has been determined that consumers who turn to organic products based on health awareness with the belief that organic ingredients are used in the production of organic products have a more positive opinion than consumers who turn to organic product shopping with environmental awareness. The health factor is the most important element in organic product preference, according to Hamilton and Hekmat (2018). Similarly, in this study, the health component stands out, and it was discovered that consumers who switch to organics because of health concerns have favourable feelings toward ingredients. The link between environmental awareness revealed by Chan (1999) and the preference for organic products is not prominent in this study. Consumers who shop for organic products because they care about the environment have a negative attitude compared to those who shop for organic items because they care about their health. Consumers who choose organic products based on health awareness have a more favourable attitude than consumers who shop organic products based on environmental awareness, according to the basic aspects they consider in their choice of organic product purchasing. It has been determined by this study that consumers' approaches to the use of organic ingredients do not vary depending on where they buy organic products. Consumers, on the other hand, choose producers, supermarkets, health, and natural product stores, according to Sandalloglu's (2014) study. Similarly, in certain countries, such as Germany, organic items are more successfully sold in market chains that specialize in natural items, as well as in hypermarkets in countries such as Switzerland and the United Kingdom (Kristensen, Juhl, \& Ostergaard, 2001). As a result of all these assessments, it has been discovered that consumer views on the use of organic ingredients in organic goods vary depending on socio-demographic factors. In our country and around the world, consumers' opinions regarding organic food products and their purchase behaviors, mostly on organic agricultural products, were investigated. What makes products organic are the ingredients used and the production methods. However, it is aimed to directly explain what consumers think about organic ingredients with this study. In this respect, the study aimed to examine the approaches of consumers regarding the ingredients of organic products within the framework of their socio-demographic characteristics. According to the findings of this study, the ingredients utilized in the manufacture of organic products are also crucial in consumer evaluations of organic products. In this context, the study is expected to provide a theoretical contribution to the marketing literature.

\section{LIMITATIONS AND SUGGESTIONS}

Regardless of whether they consume organic products or not, consumers who have a neutral point of view towards organic products have been the focus of this study. The attitudes of female consumers dwelling in a certain province toward the research issue were attempted to be determined in order also to examine the viewpoints of individuals who are unfamiliar with the subject, rather than merely the consumers with extensive experience with organic products. It was also thought that not everyone would have equal access to organic products, nor would they have equal opportunities to make these choices, and that the organic products might not be available in all consumer communities. In the coming years, marketing initiatives to inform consumers about the use of organic ingredients in the manufacture of organic products are likely to boost consumer preference for organic 
products over traditional products. Future studies in this direction could look at sociocultural and related human factors using a large sample size. It also is worth debating how to better promote organic products to current and new consumers. In addition, it can also be considered to carry out more comprehensive studies to support the production and consumption of organic products in the industrial market to prevent individual and social health risks and environmental losses.

\section{REFERENCES}

Aldrich, E. (2014). Statistics how to? https://www.statisticshowto.com/probability-and-statistics/statistics-definitions/kurtosis-leptokurticplatykurtic/ asp (08/09/2020).

Ak, I. (2004), Ecological agriculture and animal husbandry, Isparta: 4th National Zootechnical Science Congress oral presentations, 490-498.

Akaichi, F., Glenk, K., Revoredo-Giha, C. (2019). Could animal welfare claim, and nutritional information boost the demand for organic meat? Evidence from non-hypothetical experimental auctions. J. Clean. Prod, 207, 961-970.

Akın M., Çiçek, R., İnal, M., Toksarı, M., (2010). A research on the difference between the sociodemographic characteristics of consumers in Niğde province, their attitudes towards organic foods and their individual values. Dokuz Eylul University Journal of Social Sciences Institute, 12(1), 29-56.

Arasli, Z.S. and Esen, A. (2008). Organic farming industry. Turkish Development Bank Inc., Ankara: Technology Monitoring and Research Directorate Publication.

Arıkan, R. (2017). Research methods and techniques (3rd Edition). Ankara: Nobel Publishing.

Bahşi, N. ve Akça, A. (2019). A research on the determination of consumers' perspectives on organic agricultural products: The example of Osmaniye and Şanlıurfa provinces, KSU Journal of Agriculture and Nature, 22 (1): 26-34.

Bozga N. A. (2015). The perception of romanian consumer upon organic products' prices, Procedia Economics and Finance (27), 323 - 333.

Brown, T. (2006). Confirmatory factor analysis for applied research. NY: The Guilford Press.

Bryant, F.B. and Yarnold, P.R. (1995). Principal components analysis and exploratory and confirmatory factor analysis. In: Grimm, L.G. and Yarnold P.R., Eds., Reading and understanding multivariate statistics, American Psychological Association, Washington DC, 99-136.

Capatina E., Keane M. and Maruyama, S. (2018). Health shocks and the evolution of consumption and income over the life cycle, UNSW Economics Working Paper, (14), 1-50.

Curl, C.L., Beresford, S.A., Hajat, A., Kaufman, J.D., Moore, K., Nettleton, J.A., Diez-Roux, A.V. (2013). Associations of organic produce consumption with socioeconomic status and the local food environment, Multi-Ethnic Study of Atherosclerosis (MESA), 8, 769-778.

Curran, P. J., West, S. G. ve Finch, J. F. (1996). The robustness of test statistics to nonnormality and specification error in confirmatory factor analysis. Psychological Methods, 1(1), 16-29.

Çelik, S. (2013). Who buys organic food and why? A field study, Selcuk University Journal of Social Sciences Institute, 30: 93-108.

Chan, K. (2000). Market segmentation of green consumers in Hong Kong, Journal of International Consumer Marketing, 12 (2), 7- 24.

Davies, A. Titterington, J. and Cohrane, C. (1995). Who buys organic food? A porfile of the purchasers of organic food in Northern Ireland, British Food Journal, 97(10), 17- 23.

Dreezens, E., Martijn, C., Tenbült, P., Kok, G., de Vries, N.K. (2005). Food and values: an examination of values underlying attitudes toward genetically modified- and organically grown food products, Appetite, 44(1), 115-222.

Doğan, H.ve Gürel, E. (2016). Determining the attitudes and behaviours of consumers living in the central district of Kırşehir in the consumption of organic products, Journal of Gaziosmanpaşa University Faculty of Agriculture, 33 (2), 147-156.

Eryılmaz, G. A., Demiryürek K. ve Emir, M. (2015). Consumer behaviour towards organic agriculture and food products in the European Union and Turkey. Anatolian Journal of Agricultural Sciences, 30: 199-206.

Fagerli, R.A., Wandel, M. (1999), Gender differences in opinions and practices with regard to a healthy diet, Appetite, 32, $171-190$.

FiBL and IFOAM (2019). Organics international. The world of organic agriculture, Germany.

Finney, S. J. and DiStefano, C. (2013). Non normal and categorical data in structural equation modeling. G. R. Hancock ve R. O. Mueller (Ed.), Structural equation modeling: A second course. NC: Charlotte.

Gakobo, T. and Jere, M.G. (2016). An application of the theory of planned behaviour to predict intention to consume African indigenous foods in Kenya. British Food Journal, 118(5), 1268- 1280.

Gil, J., Gracia, A. and Sanchez, M. (2001). Market segmentation and willingness to pay for organic products in Spain. International Food and Agribusiness Management Review, 3(2), 207-226. 
Gök, S.A. (2008). Evaluation of Turkey in terms of organic agricultural products trade in the expanding European Union market. Ankara: Ministry of Agriculture and Rural Affairs EU Expertise Thesis.

Hamilton, K., Hekmat, S. (2018). Organic food and university students: A pilot study. Nutrition Food Science Journal. 15, 133- 134.

Harper, G.C. and Makatouni, A. (2002). Consumer perception of organic food production and farm animal welfare. British Food Journal, 104(3), 287- 299.

Hatcher, L. (1994). A step-by-step approach to using the SAS system for factor analysis and structural equation modeling, The SAS Institute Review, 325-339.

Hughner, R.S., Mcdonagh, P., Prothero, A., Shultz, C.J. and Stanton, J. (2007). Who are organic food consumers? A compilation and review of why people purchase organic food? Journal of Consumer Behaviour, 6, 1- 17.

Honkanen, P., Veerplanken B. and Olsen, S. (2006). Ethical values and motives driving organic food choice, Journal of Consumer Behaviour, 5, 420430.

Ilgar, R. (2017). Sustainability and organic agriculture in agriculture in Çanakkale. Eastern Geography Journal, 22 (37), 159-178.

İnci, H., Karakaya, E. ve Şengül, A.Y. (2017). Factors affecting organic product consumption - Diyarbakır province example, Kahramanmaraş Sütçü Imam University Journal of Natural Sciences, 20(2), 137-147.

Kalaycı, Ş. (2010). SPSS applied multivariate statistical techniques. Ankara: Asil Publishing.

Kaya, H. (2003). Organic agricultural product trade and consumer reactions in the world and in Turkey. http://www.bahce.biz/organic/organic trade. asp (01/11/2020).

Kılıç, S., Duman, O. and Bektaş, E. (2014). A field study on the marketing strategies of organic products and businesses. Business and Economics Research Journal, 5 (1), 39-65.

Kemmer, D., Anderson, A.S., Marshall, D.W. (1998). Living together and eating together: changes in food choice and eating habits during the transition from single to married/cohabiting. The Sociological Review, 46(1), 48-72.

Kline, R. B. (2005). Structural equation modeling. N.Y: The Guilford Press.

Kristensen, K., Juhl, H. J. and Ostergaard, P. (2001). Customer satisfaction: Some results for European retailing, Total Quality Management, 12(7), 890-897.

Laroche, M., Bergeron, M., and Forleo G. (2001). Targeting consumers who are willing to pay more for environmentally friend products, Journal of Consumer Marketing, 18(6), 504-507.

Lea, E. and Wosley, T. (2005). Australians' organic food beliefs, demographics and values, British Food Journal, 107(11), $855-869$.

Lockie, S., Lyons, K., Lawrence, G. and Mummery, K. (2002). Eating green: motivations behind organic food consumption in Australia. Sociologic Ruralis, 42(1), 20- 37.

Magnusson, M.K., Hursti, U.K. (2002). Consumer attitudes towards genetically modified foods. Appetite, 39, 9- 24.

Magnusson, M. (2004). Consumer perception of organic and genetically modified foods: health and environmental considerations. Uppsala: ACTA Universitatis Upsaliensis.

Magnusson, M.K., Arvola, A., Koivisto Hursti, U.-K. and Aberg, L. (2001). Attitudes towards organic foods among Swedish consumers. British Food Journal, 103(3), 209- 227.

Magnusson, M.K., Arvola, A., Koivisto Hursti, U., Aberg, L. and Sjodén, P. (2003). Choice of organic foods is related to perceived consequences for human health and to environmentally friendly behaviour. Appetite, 40(2), 109- 117.

Makatouni, A. (2002). What motivates consumers to buy organic food in the UK? Results from a qualitative study. British Food Journal, 104(3/4/5), 345- 352.

Marangoz, M. (2008). Marketing of Organic Products. Bursa: Ekin Publications.

Merdan, K. (2018). Factors affecting organic product consumption: Determination of consumers' attitudes in Gümüşhane. International Journal of Disciplines Economic and Administrative Sciences Studies, 4(8), 174- 188.

Merdan, K. (2018). Marketing opportunities and development ways in organic production. Journal of Social and Humanities Sciences Research, 5(19), 663- 672.

Muthén, B. O. ve Kaplan, D. (1985). A comparison of some methodologies for the factor analysis of non-normal likert variables. British Journal of Mathematical and Statistical Psychology, 38(2), 171- 189. 
Mhlophe, B (2016). Consumer purchase intentions towards organic food: Insights from South Africa. Business and Social Sciences Journal, 1(1), 132.

Ness, M. R., Brennan, M., Oughton, E., Ritson, C., Ruto, E. (2010). Modelling consumer behavioural intentions towards food with implications for marketing quality low- input and organic food. Food Quality and Preference, 21, $100-111$.

Onurlubaş E. ve Öztürk D. (2015). Factors that affect organic product preferences and consumer attitudes. Turkish Studies International Periodical for the Languages, Literature and History of Turkish, (10/14), 557-578.

Organic Produce Export Committee (2002). National standard for organic and bio-dynamic produce. Australian Quarantine and Inspection Service, Canberra.

Özdamar, K. (2003). Modern Bilimsel Araştırma Yöntemleri. Eskişehir: Kaan Kitabevi. Modern Scientific Research Methods. Eskisehir: Kaan Publishing.

Punch, K. (2005). Introduction to social research: Quantitative and qualitative approaches, (1st Edt.), Sage Publications.

Radic, I.; Canavari, M. (2014). Viennese consumers' preferences and willingness to pay for raspberries from Arilje, Serbia. Econ. Agro Aliment., 22, 70- 75 .

Radman, M. (2005). Consumer consumption and perception of organic products in Croatia. British Food Journal, 107 (4), 263-273.

Sandallığlu, A. (2014). Consumption of organic agricultural products and consumer trends in Adana (PhD Thesis). Adana: Çukurova University Institute of Science and Technology, Department of Agricultural Economics.

Sarıkaya, N. (2007). A field study on factors and attitudes affecting organic product consumption, Kocaeli University Journal of Social Sciences Institute, 14(7), 110-125.

Sümer N. (2000). Structural equation models: Basic concepts and sample applications. Turkish Psychology Writings, 3(6), 49-74.

Schäufele, I. and Hamm, U. (2018). Organic wine purchase behaviour in Germany: Exploring the attitude-behaviour gap with data from a household panel. Food Qual. Prefer., 63, 1- 11.

Schleenbecker, R. and Hamm, U. (2013). Consumers' perception of organic product characteristics. Rev. Appet. 71, $420-429$.

Spector, P. E. (1981). Industrial and organizational psychology: Research and practice. USA: John Wiley \& Sons, Inc.

Steenkamp, B. J and Trijp C. M. (1996). Quality guidance: A consumer-based approach to food quality improvement using partial least squares. European Review of Agricultural Economics, 23(2), 195- 215.

Stolz, H., Stolze, M., Hamm, U., Janssen, M., foodtRuto, E. (2011). Consumer attitudes towards organic versus conventional food with specific quality attributes. NJAS Wagening. J. Life Sci., 58, 67-72.

Storstad, O. and Bjorkhaug, H. (2003). Foundations of production and consumption of organic food in Norway: Common attitudes among farmers and consumers. Agriculture and Human Values, 20, 151- 163.

Sylvander, B. and Francois, M. (2006). Organic and low input food consumers: Concerns and perspectives for developing the organic market in the future. Paper at: Joint Organic Congress, Odense, Denmark.

Trierweiler, T. (2009). An evaluation of estimation methods in confirmatory factor analytic models with ordered categorical data in LISREL (Doctoral dissertation). N.Y: Fordhame University.

Ustaahmetoğu, E. ve Toklu, i. (2015). A study on the effect of attitude, health awareness and food safety on organic food purchase intention, Journal of Economic and Social Research,11(1): 197- 212.

Varoğlu, S. ve Turhan, Ş. (2016). A research on the determination of consumer trends in organic products Sakarya province example, Journal of Gaziosmanpaşa University Faculty of Agriculture, 33(3), 189-196.

Wang, J., and Wang X. (2012). Structural equation modeling: Applications using Mplus: Methods and applications. West Sussex: John Wiley and Sons.

Wägeli, S., Hamm, U. (2016). Consumers' perception and expectations of local organic food supply chains. Org. Agric., 6, $215-224$.

Wier, M., Jensen, O.K., Andersen, L.M. and Millock K. (2008). The character of demand in mature organic food markets: Great Britain and Denmark compared, Food Policy Journal, 33(5), 406- 421.

Willer, H., Yussefi- Menzler, M. ve Sorensen, N. (2008). The World of organic agriculture statistics and emerging trends. Modena, The 16 th IFOAM Organic World Congress, 143-149.

Xie, S., Deser, C., Vecchi, G., Delworth, T. (2015). Towards predictive understanding of regional climate change. Nature Climate Change Journal, 5 , 921- 930 . 
Yazdanpanah, M. and Forouzani, M. (2015). Application of the theory of planned behaviour to predict Iranian students' intention to purchase organic food. Journal of Cleaner Production, 107, 342- 352.

Zanoli, R. and Naspetti, S. (2002). Consumer motivations in the purchase of organic food: a means-end approach. British Food Journal, 104(8), 643653.

Zanoli, R. (2004). The European consumer and organic food. OMIARD University of Wales, Aberystwyth. 